needing considerable orthopaedic treatment, and about $80 \%$ requiring treatment for hydrocephalus and approximately the same percentage for urinary tract problems.

Any readjustment of the crude figures in this way does not divert from his point-for example, that there will be 300 to 400 of these patients accumulating each year at the age of 5 requiring special schooling arrangements. To put them alongside traumatic paraplegia is only relevant inasmuch as the English tradition for the fullest care and rehabilitation of traumatic paraplegia has now been established as one of the best in the world. On the other hand, it should be said in this present day we are no longer paying a very high price for the treatment of poliomyelitis, tuberculosis, and various other infections which used to constitute the bulk of paediatric practice. In this context, it would be reasonable to turn towards the provision of further care for these myelomeningocele children from such financial resources as the State, voluntary organizations, and parental contribution can provide in the hope that ultimately prevention will precede cure.

If there is an undertone to $\mathrm{Mr}$. Lightowler's theme that it might be better to do nothing when presented with these infants in the neonatal period then it is also relevant to say that the problem will often not die out at that stage, but because of accepted nursing and medical care, including the use of antibiotics, the infant will be re-presented in a more grotesque state some weeks or months later. Furthermore, the spectrum and variations of the condition are such, even to those who have seen a great deal of it, that it is unlikely that a method of infallible neurological assessment can be devised whereby the sheep can certainly be separated from the goats in the early neonatal period when such a decision would be relevant. Whatever the price of treatment, myelomeningocele would appear to be a problem which has to be faced as realistically as possible.-I am, etc.,

Division of Neurosurgery,

Division of Neurosurgery,

Kentucky, U.S.A.

1 Brocklehurst, G., Developmental Medicine and
Child Neurology, 1971, 13, 2, 147.

\section{Laparoscopic Sterilization through Cusco's} Speculum

SIR,-Mr. J. O. Greenhalf and Mr. H. R. M. Roberts (31 July, p. 304) draw attention to the risk of haemorrhage occurring from the inferior epigastric vessels after laparoscopy. This danger can be reduced to a minimum by inserting the trochar and cannula for the biopsy forceps lateral to the rectus abdominal muscle, and through an area shown to be free of vessels by transillumination. Steptoe has shown that laparoscopic sterilization is a safe and economic procedure with considerable advantages for the patients. Like many other procedures in medicine, however, laparoscopy is dangerous if it is not performed with vigilance and careful attention to the details of the technique.

The use of a small Pfannenstiel incision for sterilization is not new. Using a $3-5 \mathrm{~cm}$ incision, according to the size of the patient, it is not difficult to pick up the tubes between two fingers and to ligate them in the normal way. It is not necessary to keep these patients in hospital for long but they have more discomfort than after laparoscopy and are, of course, liable to all the complications of laparotomy.-I am, etc.,

Middlesex Hospital,

S. J. Steele

London $\mathrm{W} .1$

1 Steptoe, P. C., I.P.P.F. Medical Bulletin, April 1971, 5, No. 2, 4.

SIR,-I must protest about your misuse of the term "Laparoscopic Sterilization through Cusco's Speculum" as title for the letter by Mr. J. O. Greenhalf and Mr. H. R. M. Roberts (31 July, p. 304). The method of suprapubic incision for sterilization which they describe is the rediscovery of a technique already in use by many gynaecologists. It matters not whether a proctoscope, Cusco's speculum, or any other small retractors are used. Indeed the procedure is facilitated if the operator cares to lock the uterine cannula in position so that the uterus can be raised and rotated so as to bring the oviducts into a medial position just beneath the abdominal incision.

May I remind your correspondents that the laparoscope is a telescope with magnifying lenses, and the detail and scope afforded by it in experienced hands are much superior to naked eye inspection through a limited incision. However, it is essential that the operator possesses the correct equipment and has been properly trained in the technique.

Intra-abdominal haemorrhage from the insertion of the trocar and cannula for introduction of the biopsy forceps is entirely avoidable. The light source used should be a lamp of at least 150 watts, better still 250 or even 500 watts, and an angled vision laparoscope should be employed. This enables one to transilluminate the majority of abdominal walls, which light up like a red balloon. The blood vessels are readily located and a safe point for introduction of the trocar away from them can be selected. This fails only in the grossest of obese patients, and laparoscopic sterilization by this technique should not be attempted in such patients, although an operating laparoscope can be used alternatively.

In the case described by your correspondents blood was seen to be running down the sheath of the biopsy forceps. When the forceps was withdrawn, its site of entry into the peritoneum should have been carefully inspected through the laparoscope, and if blood was seen to be dripping down, or flowing in an arc around the parietal peritoneum, as it more usually does, then the abdominal wound should have been explored immediately and the vessel secured. The laparoscope should have been left in position so as to make a final inspection to be satisfied that the vessels had been properly sealed. Of course, a full inspection elsewhere is always necessary to make sure that no accidental damage has been caused anywhere.

Inspections of these types are carried out as routine in all my cases in Oldham, whether bleeding is suspected or not. Hundreds of cases of sterilization by laparoscopic diathermy division of the tubes have been safely performed in my department, the patients attending as day patients only. In over 3,000 laparoscopies we have had to explore the abdominal wall for bleeding on only two occasions, and for intra-abdominal bleeding only once. The death rate in Oldham is nil, and the morbidity negligible.
Laparoscopy is now accepted all over the world as a valuable, even brilliant, diagnostic and operative technique. However, the laparoscopist must possess the proper instruments, and must have been fully trained. Let us not confuse its limitations with those of the operator. If I may draw a parallel, the fact that some gynaecologists are not much good at removing the uterus by the vaginal route does not make vaginal hysterectomy a bad operation.

Laparoscopic sterilization in trained hands is a safe, rapid, simple procedure which causes a minimal disturbance to patients of only a few hours.-I am, etc.,

Oldham, Lancs

Patrick Steptoe

\section{Smallpox Vaccination}

SIR,-CSurely the herd immunity that we now have is what it has always been about. To give up this as is now contemplated, and at a time when air travel spreads disease so effectively, is a mistake. The Department of Health and Social Security circularized us with a Health Trends $^{1}$ recently claiming the whooping cough was down to almost zero when general practitioners were having the last upsurge of cases. At least I was. Was it a virus in pertussis clothing?

Has not the spread of cholera to Africa and Europe not been a warning? Who will take the blame when we suffer a smallpox epidemic in the next ten years? - I am, etc.,

Harrold,

Sydney Davies

1 Health Trends, 1970, 2, 77.

SIR,-Professor George Dick (17 July, p. 163) did not, in my opinion, give us a complete picture of the situation.

For instance, he did not disclose if the 100 deaths from vaccinations in England and Wales occurred in primary vaccinations and, if so, at what ages, and, more important still, how many of these deaths occurred as a result of vaccinations carried out in the panic conditions prevailing in the campaigns associated with the many (13) importations of smallpox to the U.K. in the last 20 years.

Furthermore, Professor Dick did not perhaps stress that the excellent measures which have controlled outbreaks in Britain in the past-namely, "prevention of importation, isolation and tracing of cases, and vaccination and surveillance of probable contacts" are rendered more difficult to achieve today in an era of fast air travel from every part of the world, including no fewer than 23 countries in which a total of no fewer than 31,000 cases of smallpox were reported last year. The standards of certification and control in some at least of these countries leave much to be desired. The risk of importation of smallpox is therefore greater than ever.

It seems to me foolhardy in these circumstances to abandon a measure which would prevent the fatalities which occurred in the past. Whatever exhortations are issued to the people, they will inevitably rush to get vaccinated as soon as an outbreak occurs. It is in these circumstances that vaccination becomes dangerous. 